\title{
The Thermal Expansion Coefficients and the Temperature Coefficients of Young's Modulus of the Alloys of Iron and Palladium*
}

\author{
By Hakaru Masumoto**, Hideo Saitô亍 ${ }^{* * *}$ and Takeo Kobayashi**
}

\begin{abstract}
The density $\rho$, Young's modulus $E$, the coefficient of linear thermal expansion $\alpha$, and the temperature coefficient of Young's modulus $e$ were measured with alloys of iron and palladium cooled down in a furnace after heating at $1000^{\circ} \mathrm{C}$ to ascertain whether a theory of Invar established previously by one of the present investigators is valid in the above alloy system or not. It was found that the both curves of $\rho$ and of $E$ to the alloying concentration showed a slight bend at the composition of about 30 at $\%$ of palladium, and also $\alpha$ showed its minimum value of $+8.9 \times 10^{-6}$ and $e$ its conspicuous positive maximum of $+139.9 \times 10^{-5}$ at 30 at $\%$ of palladium. The alloy containing 30 at $\%$ of palladium consists almost of the $\gamma$ phase after furnace cooling, but when it was cooled slower than $30^{\circ} / \mathrm{hr}$ from $800^{\circ} \mathrm{C}$, the $\gamma$ phase decreased reaching zero at the rate of $5^{\circ} / \mathrm{hr}$, accompanying an increase of $\alpha$ to $+12.3 \times 10^{-6}$, and a decrease of $e$ to $-12.5 \times 10^{-5}$, both in the order of usual alloys. According to these results, it can be confirmed that the theory of Invar mentioned above is also valid in the iron and palladium system under all conditions.
\end{abstract}

(Received May 6, 1963)

\section{Introduction}

Recently, Kussmann and Jessen(1), and Jessen(') observed that alloys of iron and palladium containing about 30 àt $\%$ of palladium showed invar-characteristics only in the temperature range of 100 to $200^{\circ} \mathrm{C}$, after cooling at a rate of $50^{\circ} / \mathrm{min}$ from $900^{\circ} \mathrm{C}$, and as long as they were not cooled below $50^{\circ} \mathrm{C}$, and that if the alloys were cooled below $50^{\circ} \mathrm{C}$, the characteristics disappeared irreversibly. When the alloys were cold worked, even if they are cooled below $50^{\circ} \mathrm{C}$, the invar-characteristics can be observed near room temperature, but if the alloys were heated to $180^{\circ} \mathrm{C}$, the characteristics also disappeared.

Kussmann and Jessen (1) pointed out that the socalled "existence of latent antiferromagnetism"

* This paper was presented at the autumn meeting of the Japan Institute of Metals, Oct. 8, 1962, Hiroshima, Japan. Published originally in Japanese in the Journal of the Japan Institute of Metals, 27 (1963), 263: The 1st report from Foundation: The Research Institute of Electric and Magnetic Alloys, Sendai, Japan.

** Foundation : The Research Institute of Electric and Magnetic Alloys, Sendai, Japan.

*** The Research Institute for Iron, Steel and Other Metals, Tôhoku University, Sendai, Japan.

(1) A. Kussmann and K. Jessen: J. Phys. Soc. Japan, 17 (1962), Suppl. B-1, 136.

(2) K. Jessen: Ann. Physik, (7) 9 (1962), 313. proposed previously by Kondorskii and Sedov(3) is not the cause of the appearance of the invar-characteristics in the above alloy system, because in alloys cooled rapidly, the curve of the Curie point to the concentration in $\gamma$-phase alloys is concave to the abscissa and shows its minimum value close to the boundary of $\gamma$-phase to the $\alpha$-phase, while the saturation magnetization of the $\gamma$-phase alloys increases monotonously to the low content palladium side, but they did not make clear the cause of the appearance of invar-characteristics in the alloy system.

According to a theory of the small expansibility of Invar previously proposed by one of the present investigators ${ }^{(4)}$, it is proper that, in a system having such magnetic properties as mentioned above, invarcharacteristics should be observed, and also by expatiating on the same theory, it may be expected that the temperature coefficient of the elastic modulus shows its negative minimum value or its positive maximum value at a composition showing invar-characteristics.

(3) E. I. Kondorskiî : Sov. Phys. JETP, 37 (1960), 1284 ; E. I Kondorskii and V. L. Sedov: J. Appl. Phys., 31 (1960), Suppl. No. 5, $332 \mathrm{~S}$.

(4) H. Masumoto : Sci. Rep. Tôhoku Univ., 20 (1931), 101 ; Kinzoku-no-Kenkyu, 8 (1931), 237 (In Japanese). 
To ascertain whether the above theory is valid in the iron and palladium alloy system or not, and to obtain stable alloys in the same system having invaror elinvar-characteristics, the temperature change of elastic modulus and the thermal expansion were measured of iron and palladium alloys after various heat treatments, and the following results were obtained.

\section{Specimens and Measurement Method}

Specimens were prepared from electrolytic iron and pure palladium, which were melted in a Tammann furnace in a hydrogen atmosphere in an alumina crucible. The melt was sucked up in a tube of fused silica, about $3 \mathrm{~mm}$ in inner diameter, and solidified in the tube. The rod was swaged at room temperature with a swaging hammer into a rod, about $2 \mathrm{~mm}$ in diameter, and then a specimens, about $10 \mathrm{~cm}$ in length, was cut from the rod for measurement.

All the specimens were heated at $1000^{\circ} \mathrm{C}$ for $1 \mathrm{hr}$ in a vacuum furnace and then furnace cooled to room temperature. A total of 24 alloy specimens were used.

The thermal expansion was measured with an apparatus designed by two of the present investigators ${ }^{(5)}$, and the mean linear expansion coefficient in the temperature range of 0 to $40^{\circ} \mathrm{C}$ was obtained. Young's modulus at $20^{\circ} \mathrm{C}$ and its mean temperature coefficient in the range of 0 to $40^{\circ} \mathrm{C}$ were determined with an apparatus for memasuring the elastic constant by means of a vibrator-controlled oscillator by using an electrostatic transducer system ${ }^{(6)}$. And also the density was determined by weighing in water.

\section{Results of Measurements and Considerations}

The results of mesurement of iron and palladium alloys heated at $1000^{\circ} \mathrm{C}$ for $1 \mathrm{hr}$ and then furnace cooled are graphically shown in Figs. 1 and 2.

Fig. 1 shows the relations of Young's modulus $E$ and of the density $\rho$ with respect to the palladium content. As seen in Fig. 1, the values of $E$ and $\rho$ for pure iron at $20^{\circ} \mathrm{C}$ were $20.1 \times 10^{5} \mathrm{~kg} / \mathrm{cm}^{2}$ and 7.80 $\mathrm{g} / \mathrm{cm}^{3}$, respectively, and they changed continuously to $11.8 \times 10^{5} \mathrm{~kg} / \mathrm{cm}^{2}$ and $12.22 \mathrm{~g} / \mathrm{cm}^{3}$ for pure palladium with increase in palladium content, both showing a slight bend at the same composition of about 30 at \% (45 wt \%) of palladium.

Fig. 2 shows the mean linear expansion coefficient $\alpha$ and the mean temperature coefficient $e$ of Young's modulus $E$ in the temperature range of 0 to $40^{\circ} \mathrm{C}$ in relation to the palladium content. It is clear from the Fig. 2 that both $\alpha$ and $e$ were of the order observed in usual alloys in a greater part of the alloying concentration range, while at the composition of 30 at $\%$ of palladium, that is, the composition showing a bend in the curves of $E$ and $\rho$ to the palladium content, $\alpha$ showed a minimum value of $+8.9 \times$

(5) H. Masumoto and T. Kobayashi: J. Japan Inst. Metals, 12 (1948), No. 6, 1 (In Japanese); Sci. Rep. RITU, A-2 (1950), 856.

(6) Y. Shirakawa and I. Oguma: J. Japan Inst. Metals, 24 (1960), 63 (In Japanese).
$10^{-6}$, and $e$ a conspicuous positive maximum value of $+139.9 \times 10^{-5}$ : the value of $e$ larger than $+100 \times$ $10^{-5}$ in the neighbourhood of room temperature could not be observed with the exception of an iron and platinum alloy ${ }^{(7)}$.

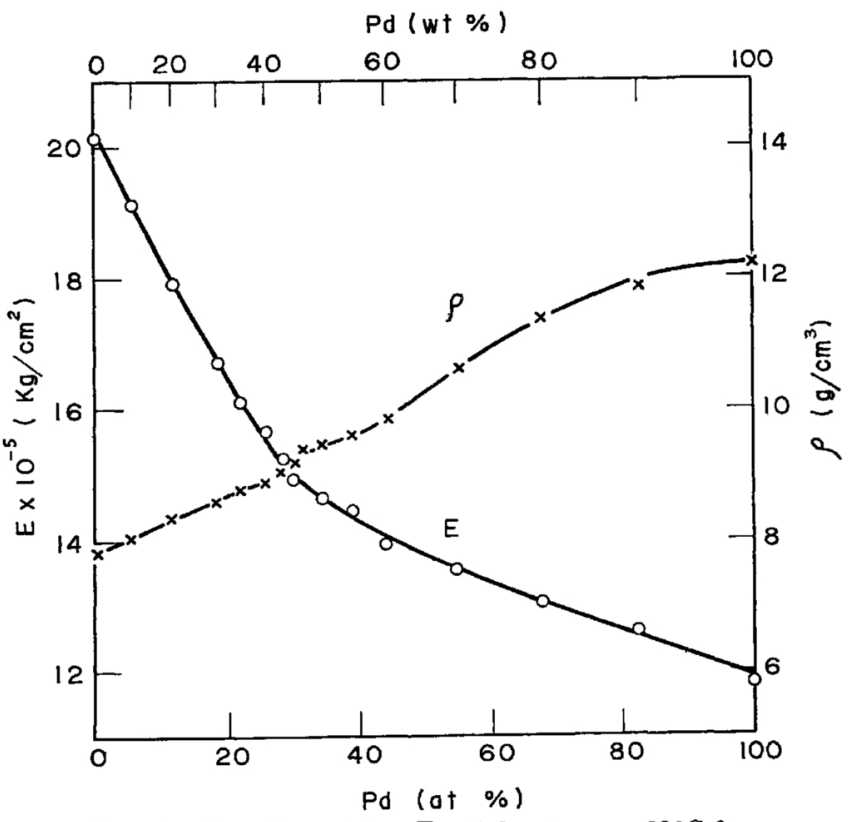

Fig. 1 Young's modulus $E$ and density $\rho$ at $20^{\circ} \mathrm{C}$ for Fe-Pd alloys furnace cooled.

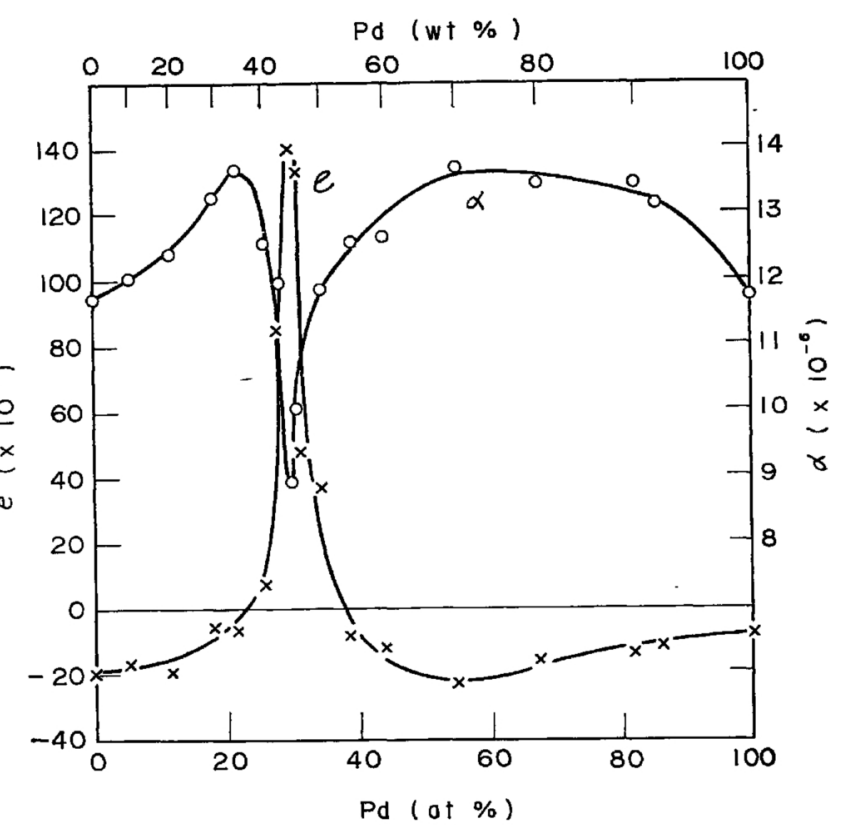

Fig. 2 Mean temperature coefficients of the thermal expansion $\alpha$ and of Young's modulus $e$ in the temperature range $0^{\circ}$ to $40^{\circ} \mathrm{C}$ of $\mathrm{Fe}-\mathrm{Pd}$ alloys furnace cooled.

In Fig. 3 is shown the relative temperature change of the square of the frequency $\left(f_{t} / f_{20}{ }^{\circ} \mathrm{c}\right)^{2}$, which is almost parallel to the temperature change of Young's modulus, obtained with the alloy containing 30 at $\%$ of palladium. Here $t$ is the measuring temperature. As seen in the Fig. $3, E$ increased continuously with the temperature, and then transfers to the para-

(7) G. I. Kataev and Z. D.Shirota: Sov. Phys. JETP, 11 (1960), 747 ; H. Masumoto and T. Kobayshi: Not yet published, read at the Autumn meeting of the Japan Inst. Metals, October 8, 1962, Hiroshima, Japan. 
magnetic state after showing a maximum near the Curie point.

To ascertain how $\alpha$ and $e$ were affected by the cooling rate, measurements were made again with the same alloy cooled at a rate of $5^{\circ} / \mathrm{hr}$ from $800^{\circ}$ to $400^{\circ} \mathrm{C}$

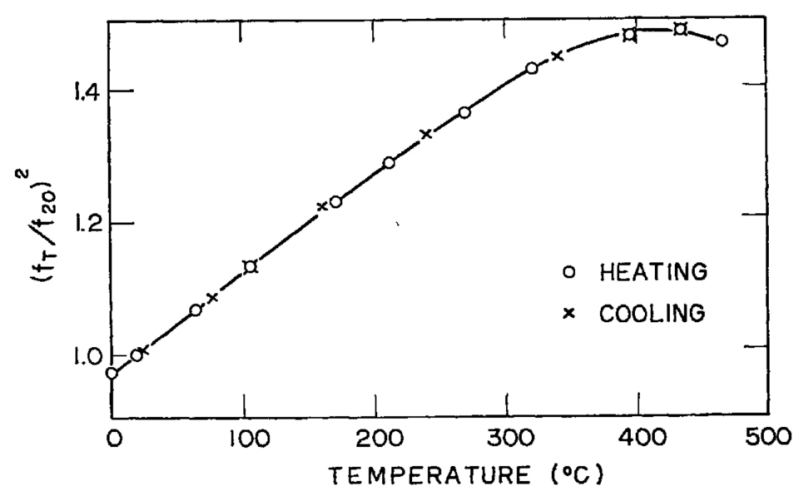

Fig. 3 Relative temperature change of the square of frequencey $f$ of a 30 at $\% \mathrm{Pd}-\mathrm{Fe}$ alloy furnace cooled.

after heating at $1000^{\circ} \mathrm{C}$ for $\mathrm{I} \mathrm{hr}$, and it was found that $\alpha$ increased to $+12.3 \times 10^{-6}$ from $+8.9 \times 10^{-.6}$, which was obtained after furnace cooling, and that $e$ decreased to $-12.5 . \times 10^{-5}$ from $+139.9 \times 10^{-5}$; that is, the values of $\alpha$ and $e$ changed to values of the usual order.

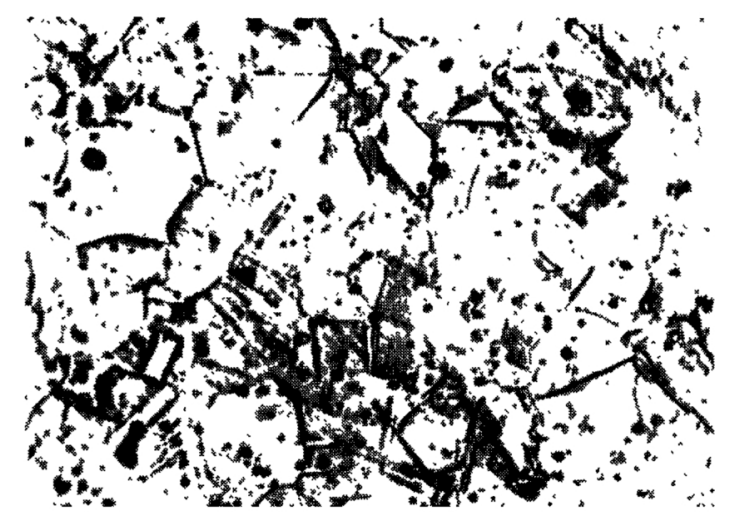

(a)

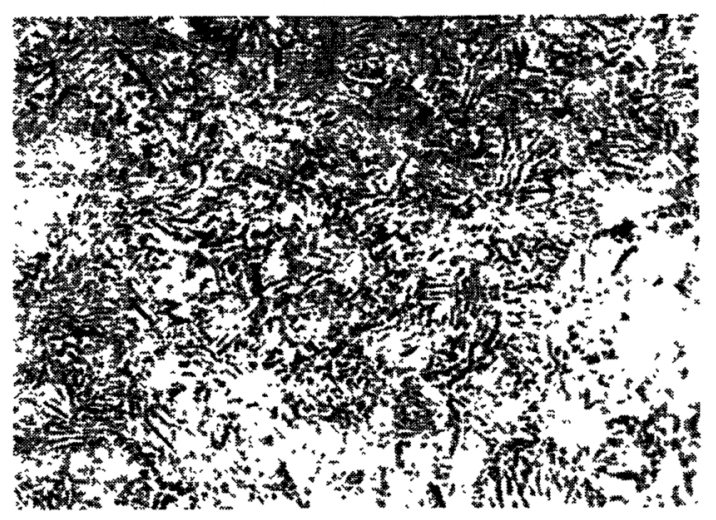

(c)

Photo. 1 Micro-structure of a 30 at $\% \mathrm{Pd}-\mathrm{Fe}$ alloy after various heat treatmets.

a: as quenched in water.

$\mathrm{b}$ : as furnace cooled.

c: as cooled at a rate of $30^{\circ} / \mathrm{hr}$ from $800^{\circ}$ to $400^{\circ} \mathrm{C}$.

$\mathrm{d}$ : as cooled at a rate of $5^{\circ} / \mathrm{hr}$ from $800^{\circ}$ to $400^{\circ} \mathrm{C}$. of the $\gamma$ phase and the $\alpha$ phase. concentration range containing less than 27 at $\%$ $(41.5 \mathrm{wt} \%)$ of palladium consists of the $\alpha$ phase, and the range containing more palladium is of the $\gamma$ phase. According to Fallot ${ }^{(8)}$, in a system cooled slowly at the rate of $4 \% \mathrm{hr}$, the range containing less than 40 at $\%$ (56 wt \%) of palladium consists of a mixture of $\alpha$ and $\mathrm{Fe}_{3} \mathrm{Pd}_{2}$ phases, and the range of more palladium is of the $r$ phase. The results shown in Fig. 1 were obtained with furnace cooled alloys; that is, the cooling rate in the case of Fig. 1 was in an intermediate state between the two extreme cases(1)(8) mentioned above. Thus, it may be confirmed that the composition showing bends in the curves of $E$ and $\rho$ to the palladium content was close to the boundary

Kussmann and Jessen ${ }^{(1)}$, and Fallot ${ }^{(8)}$ observed that, in extreme cases, after rapid cooling and slow cooling, the curves of the Curie point in the $\gamma$ phase alloys to the palladium content was concave to the abscissa and the Curie point became lower at the boundary near the $\alpha$ phase, while the saturation magnetization of these alloys increased monotonously to the low palladium side.

According to the theory of small expansibility of Invar previously proposed by one of the present investigators ${ }^{(4)}$, in a $\gamma$ phase system having such

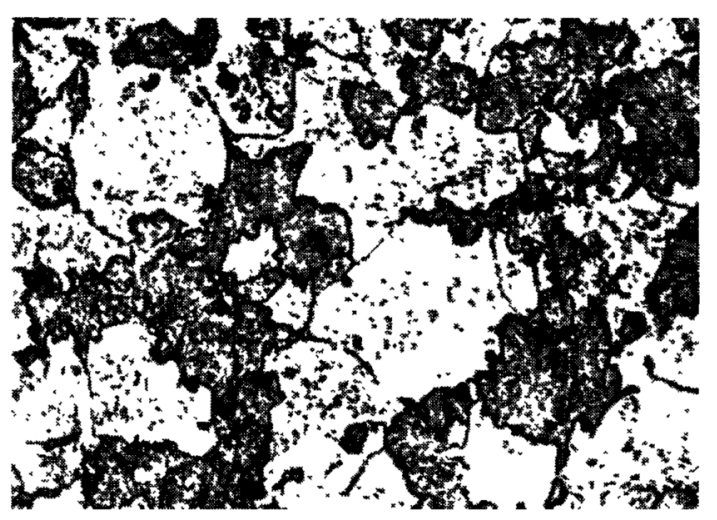

(b)

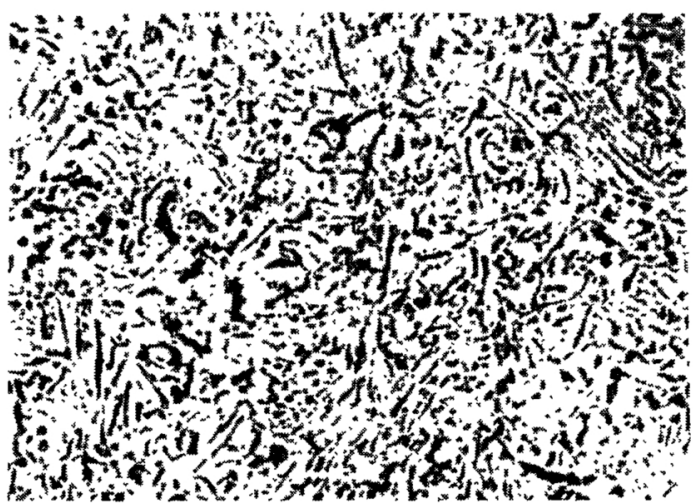

(d)
According to Kussmann and Jessen(1), in an alloy system cooled rapidly from a high temprature, the

(8) M. Fallot: Ann. de physique, 10 (1938), 291. magnetic properties, the alloy having invar-characteristics may be obtained in the vicinity of the boundary of the $\gamma$ phase and $\alpha$ phase. It may be further 
deduced from this theory that the temperature coefficient of elastic modulus would show its negative minimum or positive maximum at the same composition as mentioned above.

Finally, the relationship between $\alpha$ and $e$, and the structures of an alloy containing 30 at $\%$ of palladium was considered. The microscopic photographs taken after various heat treatments are shown in Photo. 1. As seen in the photographs, the alloy presented only the $\gamma$ phase after quenching in water from $1000^{\circ} \mathrm{C}$, and the alloy cooled in the furnace was also composed mainly of the $\gamma$ phase. When the alloy was cooled from $800^{\circ}$ to $400^{\circ} \mathrm{C}$ at a slower rate than $30^{\circ} / \mathrm{hr}$, two phases decomposed were observed.

However, it could not be confirmed whether the $\alpha$ phase was precipitated from the $\gamma$ phase, or the $\gamma$ phase was decomposed to the $\alpha$ phase and the $\mathrm{Fe}_{3} \mathrm{Pd}_{2}$ phase as concluded by Fallot ${ }^{(8)}$. In either case the quantity of the $r$ phase is decreased by slower cooling. Therefore, it can be warranted that with the decrease of the cooling rate, the minimum value of $\alpha$ increases and the positive maximum value of $e$ decercases and that these values would reach the final ones of the usual order after slow cooling at a rate of $5^{\circ} / \mathrm{hr}$.

Thus, it has been made clear that the theory of Invar (4) mentioned above is valid in the iron and palladium system under all conditions.

\section{Summary}

Using iron and palladium alloys cooled in a furnace to room temperature from $1000^{\circ} \mathrm{C}$, the density $\rho$ and
Young's modulus $E$ at $20^{\circ} \mathrm{C}$, and the mean linear expansion coefficient $\alpha$ and the mean temperature coefficient of Young's modulus $e$ in the temperature range of 0 to $40^{\circ} \mathrm{C}$ were measured, and the following results were obtained :

(1) Both curves of $\rho$ and of $E$ to the palladium content showed a slight bend at the composition of about 30 at \% (45 wt \%) of palladium.

(2) In the same composition of 30 at $\%$ of palladium $\alpha$ showed a minimum value of $+8.9 \times 10^{-6}$, and $e$ a positive maximum value of $+139.9 \times 10^{-5}$.

(3) In the alloy containing 30 at $\%$ of palladium, it consisted of $\gamma$ phase in the rapidly cooled state, and two phases were observed, when the alloy was cooled slower than $30^{\circ} / \mathrm{hr}$ from $800^{\circ} \mathrm{C}$, being accompanyed by a change of values of $\alpha$ and $e$ to those of the usual order, that is, $+12.3 \times 10^{-6}$ and $-12.5 \times 10^{-5}$, respectively.

(4) According to the results mentioned above, it was confirmed that the theory of the small expansibility of Invar previously proposed by one of the present investigators is valid in the iron and palladium system.

\section{Acknowledgement}

The present investigators wish to express their sincere thanks to Mr. Y. Murakami and Mr. S. Sawaya of the Research Institute of Electric and Magnetic Alloys for their kind assistance in making the measurements, and also to Mr. Y. Sugai and Mr. T. Abe of the Research Institute for Iron, Steel and Other Metals for taking the microscopic photographs. 